\title{
COMPARISON OF ENVIRONMENTAL RICHNESS IN NATURAL FOREST AND HOMEGARDENS: A CASE STUDY FROM NACHCHADUWA CATCHMENT
}

\author{
P B Dharmasena \\ Field Crops Research and Development Institute, Maha Illuppallama
}

An attempt was made to develop an assessment indicator combining the most important parameters which decide the environmental richness of a plant community. Stratal coverage, species richness and plant density were included in the following formula to describe the environmental richness as:

$E R=S . /\left(K_{L} N_{L}+K_{M} N_{M}+K_{S} N_{S}\right)$, Where ER is environmental richness, $K$ is a coefficient to represent stratal coverage and $N$ is the number of plants per 100 sq.m for large (L), medium (M) and small (S) canopy types and $S$ is the number of species per 100 sq. $\mathrm{m}$.

A plant composition survey was carried out in a selected forest block of $25 \mathrm{~m} \mathrm{x} 25 \mathrm{~m}$ at Paindikulama in the Nachchaduwa watershed in 1997 to assess the environmental richness in natural forest. A comparison was then made with results obtained from a previous homegarden survey conducted in the same watershed.

During the survey 31 plant species were identified and the total number of plants surveyed was 1360 . The average plant density was 218 per $100 \mathrm{~m}^{2}$. Environmental richness of this forest block was found as high as 108 whereas the value for homegardens has ranged from 0.7 to 34.7 . Results also revealed that the contribution made to environmental richness was higher $(75 \%)$ by small canopy plants compared to large $(3 \%)$ and medium $(22 \%)$ categories. This may be due to the selective felling of large trees and subsequent emergence of small plants in the exposed patches. Results conclude that man made homegardens could only achieve about one third of the environmental richness of natural forest.

Proceedings of the Third Annual Forestry Symposium 1997 of the Department of Forestry and Environmental Science, University of Sri Jayewardenepura, Sri Lanka 